\title{
Uma Pesquisa-ação da Metodologia Lean Startup em um Empreendimento de Software
}

\author{
Nágila N. J. Torres ${ }^{1}$, Eduardo L. Guerra ${ }^{1}$, Adailton M. Lima ${ }^{2}$ \\ ${ }^{1}$ Faculdade de Sistemas de Informação- Universidade Federal do Pará (UFPA) \\ Castanhal - PA - Brasil \\ nagila.ufpa@gmail.com, \{eguerra,adailton\}@ufpa.br
}

\begin{abstract}
In the recent years there is a growing on creation of startups and also models of business management, mainly influenced by different inceptives by investors and governments. This study presents an evaluation of the Lean Startup methodology, under the context of an action research on developing a new enterprise software entrepreneurship. This study emphasizes the use of that methodology by entrepreneurs attending the final year of a course in the field of computing. The research project evaluated the difficulties, facilities and impacts on the application of the methodology for the development of a Startup. Finally, we have a report with results from the experience of conducting this field study.
\end{abstract}

Resumo. Com os mais diversos incentivos para a formação de novos empreendedores e também novas empresas, tem-se visto nos últimos anos o desenvolvimento surpreendente de Startups digitais e também modelos de gestão de negócios para tais. Este trabalho consiste em uma avaliação da metodologia Lean Startup, sob o contexto de uma pesquisa-ação no desenvolvimento de um novo empreendimento da indústria de software. Este estudo enfatiza a utilização deste tipo de metodologia por empreendedores cursando o último ano de graduação de um curso da área de computação. A pesquisa em questão avaliou as dificuldades, facilidades e impactos na aplicação da metodologia durante o desenvolvimento de uma Startup. Por fim, tem-se um relatório com resultados das experiências vivenciadas durante o estudo avaliativo.

\section{Introdução}

Existem diversas políticas governamentais pelo mundo de fomento ao desenvolvimento do empreendedorismo, como por exemplo, o programa Startup Brasil ${ }^{1}$ e o brasilmaisTI ${ }^{2}$ do Ministério de Ciência, Tecnologia e Inovação (MCTI), o que destaca a relevância estratégica deste assunto. Instituições como a Organização das Nações Unidas (ONU) e governos de países como EUA, Israel, Índia e Brasil, têm investido maciçamente em programas dessa natureza, com a convicção de que o empreendedorismo é capaz de trazer benefícios como crescimento econômico e até diminuição de desigualdades sociais (Grin et al., 2012).

Nesse contexto, tem-se visto o desenvolvimento surpreendente do empreendedorismo digital no mundo, alavancado por Startups, representadas por gigantes como: Facebook, Peixe Urbano e Groupon. Junto a esses novos modelos, novas metodologias surgiram, a

${ }^{1}$ http://startupbrasil.mcti.gov.br

${ }^{2}$ http://www.brasilmaisti.com.br/ 
fim de acompanhar o ritmo acelerado de inovação e atender principalmente a um segmento específico: as empresas conhecidas como Startups.

Apesar de existir um cenário otimista, pouco se tem estudado sobre Startups, e também sobre metodologias que aumentam sua chance de "sobrevivência" em um mercado ainda desconhecido.

Uma pesquisa realizada pela Harvard Business School mostrou que 75\% de todas as Startups falham e que isso pode ser decorrente do uso de métodos tradicionais (Blank, 2013). Ries (2012a) afirma que os métodos tradicionais de administração não se aplicam as Startups, isto porque estes métodos baseiam-se em previsões que funcionam melhor em ambientes estáticos, em detrimento de ambientes onde as Startups estão inseridas, em que as mudanças são frequentes e os riscos maiores.

Assim, esse trabalho se torna relevante, pois objetiva estudar como a metodologia Lean Startup, ferramenta para a gestão de negócios, auxilia na permanência de uma Startup digital em um ambiente de incertezas. Além disso, este trabalho se justifica, pois visa suprir a necessidade de ser ter mais e melhores estudos empíricos de desenvolvimento ágil de software (Dyba \& Dingsoyr, 2008), pois embora esse novo movimento esteja se expandindo cada vez mais, há uma escassez de pesquisas acadêmicas sobre a metodologia Lean Startup (Gustafsson \& Qvillberg, 2012); bem como trazer para a realidade regional a aplicação de uma metodologia para criação de Startups para motivar a participação de empresas do Norte do Brasil em programas de apoio ao empreendedorismo.

O restante desse trabalho está organizado da seguinte maneira: a Seção 2 define o escopo dessa pesquisa; a Seção 3 apresenta o referencial teórico; a Seção 4 apresenta os trabalhos relacionados; a Seção 5 apresenta o processo de condução de pesquisa; a Seção 6 descreve os resultados e, por fim, na Seção 7 são apresentados as conclusões e trabalhos e futuros.

\section{Objetivo do Trabalho}

O objetivo deste trabalho é acompanhar o desenvolvimento da Startup de Inovação tecnológica, chamada de Rota Urbana ${ }^{3}$, para investigar as práticas propostas pela metodologia Lean Startup e avaliar as dificuldades, facilidades e impactos durante a aplicação da mesma no desenvolvimento desta Startup. Este estudo foi conduzido através das técnicas da pesquisa-ação. Com isso, pretende-se divulgar os resultados e compartilhar as experiências com empreendedores em geral, especialmente os estudantes na área da computação no Brasil.

\section{Referencial Teórico}

Nesta Seção é exposta uma sucinta contextualização que serviu como base para o desenvolvimento deste trabalho.

\subsection{Startup}

\footnotetext{
${ }^{3}$ Disponível em http://www.rotaurbana.net.br
} 
Uma Startup, por definição, é uma catalisadora que transforma ideias em produtos. Sua descrição está intimamente ligada com o conceito de empresas nascentes que estão à procura de mercado para seu produto inovador, inseridas em um contexto incerto.

Segundo a definição de Ries (2012a, p.24), "Startup é uma empresa ou uma instituição humana que se constrói nos mais diversos ramos e que surge espontaneamente a condição de extrema incerteza, tem em sua essência a inovação para criar produtos e serviços os quais pretendem revolucionar o mercado."

É importante ressaltar que há distinção entre uma pequena empresa comum de uma Startup. Segundo Blank e Dorf (2012) Startups não são simplesmente versões menores de grandes empresas. Baseado nisso, uma empresa iniciante, ligada a qualquer tipo de negócio, que não esteja focada para a inovação de produtos ou serviços e, portanto dispensada para os riscos de incertezas, não é uma Startup. Meira (2013, p.196) acrescenta que "nem todo novo negócio é uma Startup, apesar de toda Startup ser um novo negócio".

\subsection{Modelos de Gestão de Negócios Inovadores}

Os modelos de negócio são moldes de como conduzir uma organização para a qual ele foi designado. Especifica padrões, técnicas e ferramentas necessárias para atingir este fim. Osterwalder e Pigneur (2010), descrevem o modelo de negócio como a forma na qual uma organização cria, entrega e captura valor. Essenciais para o crescimento "sustentável" de um negócio. Nesse sentido, surgem modelos adequados ao contexto das Startups, denominados aqui de modelos de gestão de negócios inovadores, os quais têm substituído os tradicionais e se adaptado às mudanças nesse novo cenário, que têm como fatores críticos e fundamentais a agilidade e o dinamismo para atender as exigências das Startups.

\subsection{Lean Startup}

A metodologia Lean Startup ou Startup Enxuta tem suas raízes derivadas de ideias da manufatura enxuta, com alguns ajustes e refinamentos das abordagens de outros modelos de gestão de negócios inovadores, combinadas com as metodologias ágeis de desenvolvimento de software e adaptadas ao empreendedorismo atual (Ries, 2012a).

Ries (2012a) define a Startup Enxuta como uma abordagem com princípios para desenvolvimento de novos produtos, criada para conduzir o negócio a uma direção sustentável. Sustentável no sentido de construir produtos que entreguem valor ao cliente e eliminar tudo o que não contribui para isso.

Essa metodologia concentra-se na experimentação e feedback dos clientes, pois ajuda as Startups a desenvolverem produtos e serviços inovadores em uma relação estreita com eles. O elemento central é um processo cíclico composto das fases: construir, medir e aprender (Patz, 2013). Conforme Figura 1. Esta pode ser representada de maneira mais didática na 4 


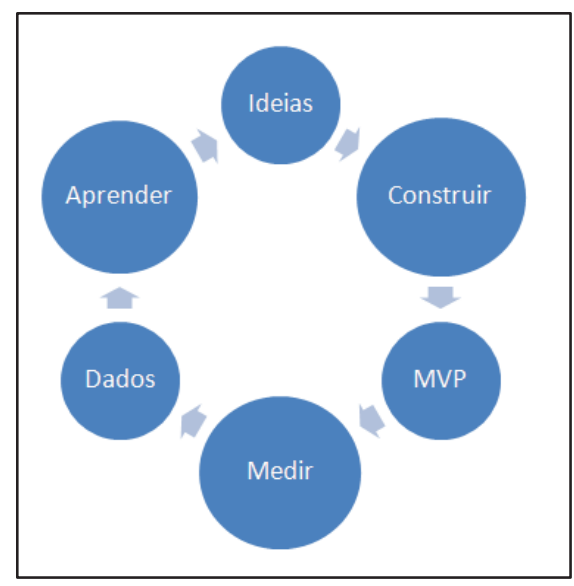

Figura 1. Ciclo de Feedback Construir - Medir - Aprender. Fonte: Ries, 2012.

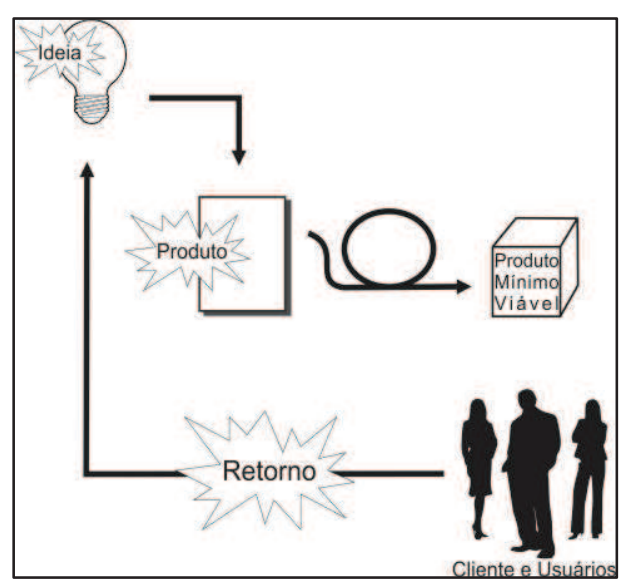

Figura 2. Ciclo de Feedback do Lean Startup. Fonte: Garcia, 2012.

\section{- Ideias}

A metodologia sugere iniciar o processo através da definição da visão do negócio para identificar a estratégia, sendo que visão segundo Ries (2012a), é caracterizada como a descrição do negócio. Partindo desse pressuposto, são definidos os perfis dos possíveis usuários. Após isso, a visão é decomposta nas hipóteses de valor e crescimento. As hipóteses de valor são formuladas para testar se o produto ou serviço de fato fornece valor aos clientes e, as hipóteses de crescimento têm a finalidade de verificar se o crescimento do produto está dentro do esperado para o negócio (Ries, 2012a).

\section{- Construir e MVP}

Essas fases envolvem a definição de indicadores (indicam o quão as hipóteses podem ser verdadeiras), funcionalidades e a construção destas últimas, fundamentais para se construir o Produto Mínimo Viável (MVP), que é um experimento que fornece indicadores mais exatos e tem como objetivo validar as hipóteses. Este pode variar desde testes muito simples até protótipos reais.

\section{- Medir e Dados}

O MVP é testado na fase de medir por um período breve definido pela Startup. Para garantir a efetividade desta fase os dados são colhidos, analisados e avaliados para determinar se a Startup está fazendo ou não um progresso real.

\section{- Aprender}

Após a medição pode-se perceber que se deve perseverar a estratégia inicial ou realizar o "pivô", que consiste em mudanças específicas na estratégia. Para ambas as situações, a aprendizagem é que discerne para que lado da bifurcação deve-se seguir e, em seguida, o ciclo Construir, Medir e Aprender deve ser novamente percorrido, de forma mais ágil e com reajustes na estratégia.

\subsection{Pesquisa-ação}

A pesquisa-ação é um método de pesquisa intervencionista que permite ao pesquisador testar hipóteses sobre o fenômeno de interesse para provocar mudanças no cenário 
(Lindgren, et al., 2004). Esse método permite que o pesquisador intervenha na prática conduzida e possa direcionar o estudo a caminhos adequados.

Ela é um modelo aplicado a qualquer situação que exija investigação sobre a prática sob a intervenção de um pesquisador, com o objetivo, neste trabalho, de investigar sobre o Lean Startup. Esta metodologia possui fases que descrevem cada etapa do ciclo, são elas: fase exploratória, fase de planejamento, fase de ação, implementação e fase de avaliação. Conforme ilustrado na Figura 3.

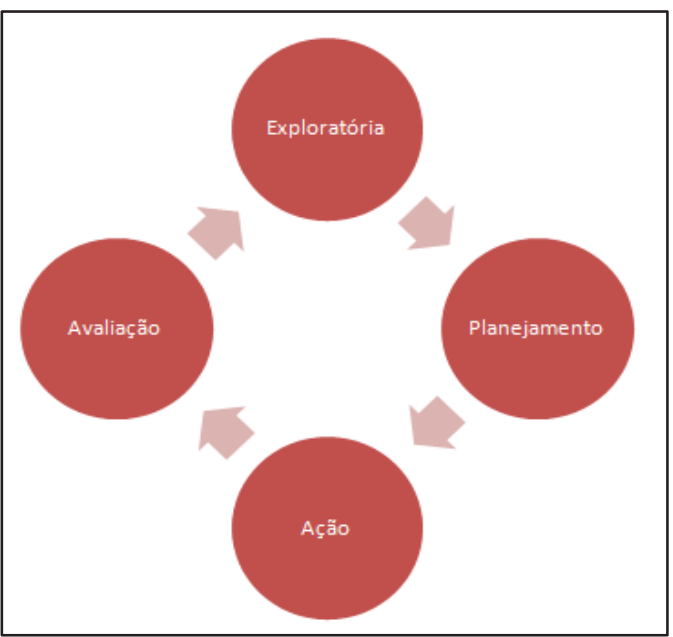

Figura 3. Ciclo da metodologia Pesquisa-ação. Fonte: Oliveira, 2005.

\section{- Exploratória}

Esta fase tem o objetivo e explorar e diagnosticar a situação e necessidades dos atores (Stakeholders), bem como obter o comprometimento da equipe. Também são informados sobre os objetivos do estudo e a metodologia que será empregada.

\section{- Planejamento}

Essa fase diz respeito à elaboração da problemática e priorização do trabalho, ou seja, definir quais as hipóteses a serem investigadas primeiro para uma determinada situação. O início da prática começa aqui.

- Ação

Engloba medidas práticas baseadas nas etapas anteriores: difusão de resultados; definição de objetivos alcançáveis por meio de ações concretas e execução da prática planejada Thiollent (1997 como citado em Krafta et al., 2007).

\section{- Avaliação}

Apresenta dois objetivos principais: verificar os resultados das ações no contexto organizacional da pesquisa e suas consequências e extrair ensinamentos que serão úteis para continuar a experiência e aplicá-la em estudos futuros (Krafta et al., 2007). Tem-se também a elaboração do relatório das atividades realizadas ao final do estudo.

\section{Trabalhos relacionados}

Apesar do crescente estudo acerca da metodologia Lean Startup, têm-se ainda poucos trabalhos sobre relatos de aplicações desta abordagem, principalmente, no que se refere 
à aplicação no contexto de Startups de software. Dessa maneira, são explicitados, a seguir, dois trabalhos relacionados a este.

Em (Braga 2012) o autor mostra como os modelos geridos para a aplicação em negócios, tais como Lean Startup e Modelo de Negócio Canvas, podem afetar no sucesso ou insucesso de uma Startup digital. Até o final do estudo a Startup não teve resultados que pudessem caracterizar seu sucesso ou fracasso. Entretanto, consegue discutir como algumas técnicas utilizadas puderam nortear o caminho a ser percorrido pela Startup.

Em [Gustaffsson and Qvlliberg 2012] tem como objetivo primordial a avaliação da metodologia Lean Startup, sob a óptica de um estudo de caso e pesquisa-ação como método avaliativo, dentro de um contexto de uma empresa iniciante manufatureira. As técnicas da metodologia foram aplicadas e analisadas a fim de identificar possíveis barreiras e desafios à sua implementação. Os autores afirmam que a velocidade pela qual a empresa podia se mover através de cada iteração foi drasticamente menor em comparação com as empresas de desenvolvimento de software.

Todos os dois trabalhos se assemelham a este por estudar o Lean Startup. Entretanto, algumas análises que se pretendem fazer no presente trabalho, tais como a descrição detalhada da execução do processo e o destaque de quais abordagens da metodologia foram proeminentes, não são encontradas no primeiro trabalho. O segundo trabalho é realizado em uma empresa manufatureira onde fica mais difícil a viabilização da construção do MVP em comparação com as Startups de software.

\section{Processo de Condução de Pesquisa}

Durante o estudo sentiu-se a necessidade de um modelo, onde se podia conduzir a pesquisa e simultaneamente aplicar o Lean Startup, para isso, realizou-se uma revisão das duas metodologias (Lean Startup e Pesquisa-ação), na qual foi identificada a similaridade das fases entre os modelos estudados e, levando em consideração que as duas metodologias baseiam-se em ciclos, fez-se necessário uma proposta original para encaixe destas, conforme ilustrado na Figura 4.

A Figura 4 exibe a concepção das quatro fases macros propostas neste trabalho: (1) conhecimento, (2) planejamento, (3) execução e (4) medição e análise. As fases são descritas a seguir:

\section{- Fase de Conhecimento}

Esta fase reúne aspectos das fases exploratórias e de ideias, das metodologias pesquisaação e Lean Startup, respectivamente. São realizadas pesquisas de caráter exploratório para identificar necessidades emergentes acerca do negócio; apresentação de como o estudo será conduzido; elaboração dos problemas, hipóteses e a definição de perfis.

\section{- Fase de Planejamento}

Essa fase refere-se ao planejamento das etapas do ciclo em questão. É realizada a divisão de equipes multidisciplinares, priorização das hipóteses por níveis de importância dentro do negócio, indicadores e funcionalidades que testarão as hipóteses.

\section{- Fase de Execução}


Esta refere-se a execução de tudo o que foi planejado. Aqui são construídas as funcionalidades e ferramentas para testar efetivamente as hipóteses.

\section{- Fase de Medição e Análise}

Aqui onde os dados são medidos e analisados para obtenção dos ensinamentos acerca dos resultados que poderão resultar em mudanças ou não. Além disso, os resultados das ações de pesquisa são verificados e divulgados.

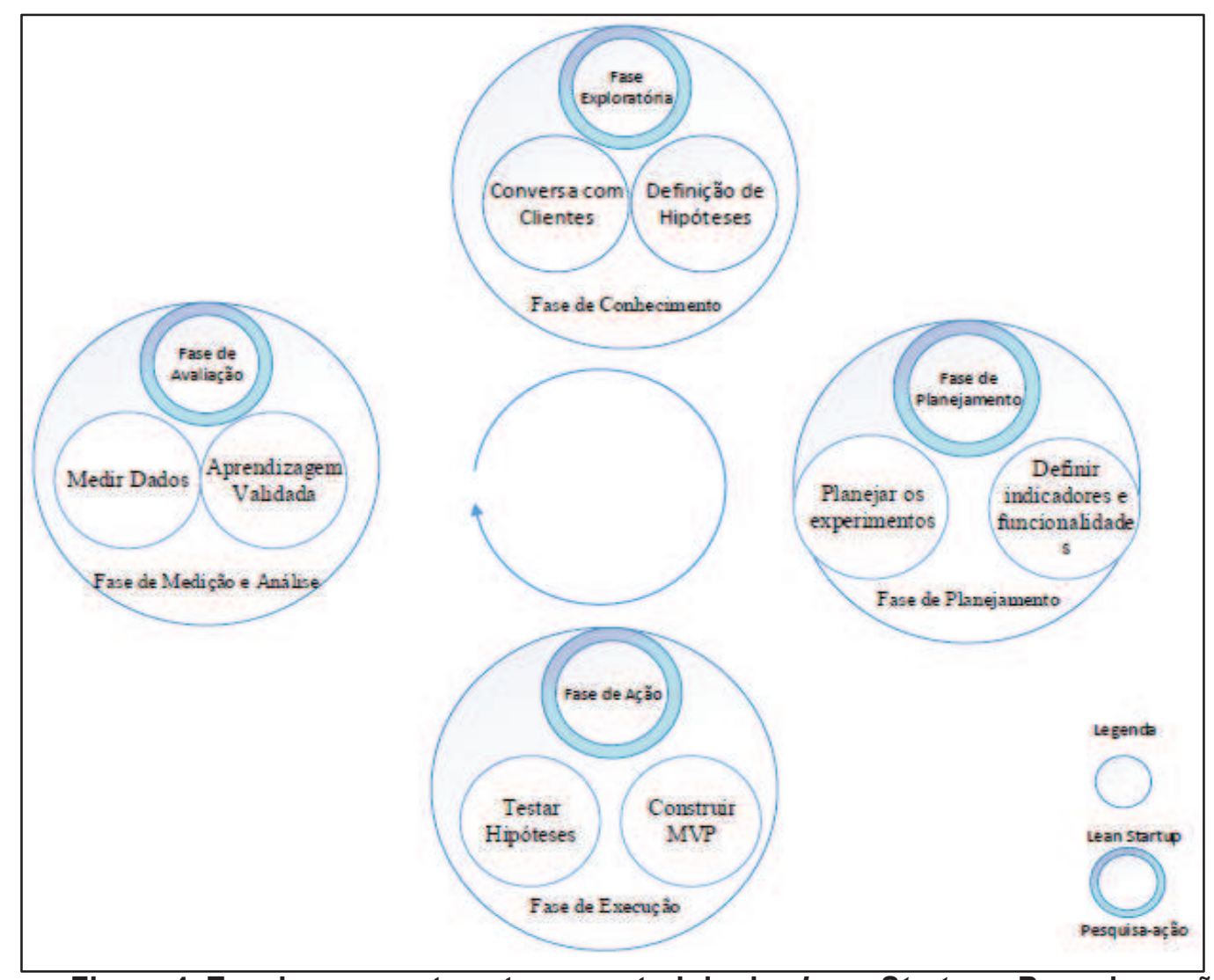

Figura 4. Encaixe proposto entre as metodologias Lean Startup e Pesquisa-ação.

\section{Resultados}

Foram 2 ciclos realizados, o que compreende o período de 19 de agosto a 22 de dezembro. O primeiro de 3 meses e o segundo de 27 dias. A análise de cada um dos ciclos será apresentada a seguir, baseada na estrutura da Figura 4. É importante acrescentar que parte da interação entre a pesquisadora e a Startup se deu de forma remota, pois esta última se encontra em outra cidade.

\subsection{Ciclo I}

\section{- Fase Exploratória}

O Startup já tem um produto inacabado, com usuários ativos e, acredita que possui um ótimo produto com ótimas funcionalidades. Sua concentração de esforços se dá na codificação das funcionalidades do sistema, as quais são feitas, sem, no entanto, o conhecimento das reais necessidades dos usuários. Atualmente não é seguido nenhum modelo de negócio estruturado 
A Startup também faz uso da ferramenta Google Analytics, que é utilizada para colher alguns tipos de métricas. No entanto, não esclarece se determinadas funcionalidades estão sendo aceitas ou não pelos usuários.

Inicialmente foi realizada uma reunião para a realização da fase exploratória. A equipe foi bastante receptiva e muita entusiasmada com a ideia de um modelo de gestão que ajudasse a descobrir o caminho adequado.

Nesta fase foi definida também a visão do negócio; perfil dos usuários e identificação das hipóteses em um documento compartilhado e acessível a todos os envolvidos no projeto. As hipóteses do negócio definidas se encontram na Tabela 1.

Tabela 1. Hipóteses de Valor e Crescimento definidas (Ciclo I).

\begin{tabular}{|c|c|}
\hline \multicolumn{2}{|r|}{ Hipóteses de Valor } \\
\hline 1 & $\begin{array}{l}\text { O usuário tem interesse em saber onde estão as paradas da rota da linha de ônibus } \\
\text { selecionada. }\end{array}$ \\
\hline 2 & O usuário tem interesse em saber pontos de referência de uma parada. \\
\hline 3 & O usuário tem interesse em cadastrar as paradas que ele conhece. \\
\hline 4 & $\begin{array}{l}\text { O usuário tem interesse em saber quais linhas de ônibus que passam em } \\
\text { determinados pontos da cidade. }\end{array}$ \\
\hline 5 & $\begin{array}{l}\text { O usuário tem interesse em ter uma listagem de todas as linhas de ônibus da } \\
\text { cidade para selecionar cada uma delas para visualizar sua rota. }\end{array}$ \\
\hline \multicolumn{2}{|r|}{ Hipóteses de Crescimento } \\
\hline 6 & Usuário recomenda o uso do sistema para outros dois amigos. \\
\hline 7 & $\begin{array}{l}\text { Usuário compartilha com os amigos uma rota que criou (por exemplo o caminho } \\
\text { qualquer contexto de rota - que alguém deveria para chegar a casa de um } \\
\text { conhecido). }\end{array}$ \\
\hline
\end{tabular}

\section{- Fase de Planejamento}

Foi realizado em conjunto, a definição dos indicadores e funcionalidades vinculados as hipóteses definidas anteriormente. Durante a confecção do documento surgiram muitas dúvidas (reportadas por $e$-mail) a respeito das técnicas, pois alguns conceitos ficaram confusos. Mediante isso, foi marcada uma segunda reunião presencial para esclarecer as dúvidas a respeito do documento.

\section{- Fase de Execução}

Esta fase foi realizada de maneira remota e colaborativa com os integrantes da Startup. Os responsáveis pela codificação ficaram incumbidos de construir as funcionalidades (não expostas aqui) pertinentes ao MVP para a validação das 7 hipóteses.

Apesar da utilização do modelo de gestão Lean Startup já está definido, a equipe do Rota Urbana estava concentrada em outras funcionalidades não exigidas no ciclo, Ries (2012a) afirma que qualquer tentativa do não cumprimento das tarefas da Startup é uma forma de desperdício. Em meio aos ocorridos apenas 4 funcionalidades foram construídas e testadas, correspondentes as hipóteses de valor (2, 3, 4 e 5). 


\section{- Fase de Medição e Análise}

Foi criado um usuário com perfil de administrador no sistema web do Rota Urbana para consulta de indicadores provenientes das funcionalidades já desenvolvidas.

Os experimentos provenientes das quatro funcionalidades desenvolvidas foram testados durante o período de um mês, sendo que a duração total do Ciclo I foi concluída em três meses. O total de visitas no sistema Rota Urbana ocorridas durante o período de teste foi de 1989, com uma taxa de aceitação e rejeição de $51 \%$ e $49 \%$, respectivamente. A taxa de aceitação revela que o usuário interagiu de alguma forma com o sistema (visitas efetivas) e, a taxa de rejeição afirma que o usuário entrou no sistema, porém não obteve nenhum tipo de interação com ele. Os resultados do experimento se encontram na Tabela 2, calculados a partir da taxa de aceitação.

Tabela 2. Resultado dos Experimentos (Ciclo I).

\begin{tabular}{|l|l|l|}
\hline \multicolumn{2}{|c|}{ Indicadores } & \multicolumn{1}{c|}{ Resultados dos Experimentos } \\
\hline $\mathbf{2}$ & $\begin{array}{l}\text { Quantidade de cliques sobre as paradas } \\
\text { para abrir o texto de informações e pontos } \\
\text { de referência da mesma. }\end{array}$ & $\begin{array}{l}\text { [Erro de construção de funcionalidade, era } \\
\text { para ser obtido o percentual de visitas que } \\
\text { clicaram, mas foi obtida apenas a quantidade } \\
\text { de cliques] 360 cliques nas paradas de ônibus }\end{array}$ \\
\hline $\mathbf{3}$ & $\begin{array}{l}\text { Percentual de usuários que cadastra as } \\
\text { paradas maior que a metade do total de } \\
\text { usuários que acessaram nesse período. }\end{array}$ & 1 usuário cadastrou paradas (0,098\%) \\
\hline $\mathbf{4}$ & $\begin{array}{l}\text { Percentual de usuários (em relação aos } \\
\text { usuários ativos) que acessa a página } \\
\text { inicial do sistema e seleciona dois pontos } \\
\text { para saber linhas que passam perto desses } \\
\text { dois pontos. }\end{array}$ & $\begin{array}{l}\text { [Erro de construção de funcionalidade, foi } \\
\text { obtido apenas a quantidade de rotas traçadas] } \\
3276 \text { rotas traçadas }\end{array}$ \\
\hline \multirow{5}{*}{$\begin{array}{l}\text { Percentual de usuários (em relação aos } \\
\text { usuários ativos) que navega até a página } \\
\text {,Todas as Rotas para visualizar rota(s) } \\
\text { específica(s) e consecutivamente clica nas } \\
\text { linhas desejadas. }\end{array}$} & $\begin{array}{l}623 \text { visitas clicaram em visualizar rotas } \\
(61,43 \%)\end{array}$ \\
\hline
\end{tabular}

Como percebido na Tabela 2, ocorreram algumas falhas durante a construção dos experimentos, tanto por parte da Startup, quanto por parte da pesquisadora, discutidas abaixo.

\section{- Discussão dos resultados}

O resultado ocorrido não foi o esperado, pois durante o planejamento e a execução, houve algumas falhas que prejudicaram esta análise final. Podem-se pontuar as falhas que ocorreram no decorrer do desenvolvimento deste projeto:

- Algumas funcionalidades que visavam testar suas respectivas hipóteses não foram construídas, por algumas razões, a saber: a equipe estava concentrada em outras funcionalidades que não foram definidas no ciclo; a divisão de tarefas na equipe não estava equilibrada corretamente; a equipe estava engajada em outro projeto e, outras 
funcionalidades definidas estavam complexas para serem desenvolvidos no tempo estipulado para o ciclo.

- Faltou uma maior formalização do prazo para a fase de execução, isso acarretou em um período extenso de três meses do ciclo e atrasos no fechamento das fases.

- Metade das funcionalidades construídas que validariam as hipóteses estava incorreta, pois o documento compartilhado não estava compreensível para todos e, as funcionalidades não estavam descritas corretamente, isso foi determinante para a não validação das hipóteses definidas. Assim, não se teve como discernir se a Startup está ou não fazendo um progresso na direção do ideal, pois não se sabe quantos usuários estão engajados com as funcionalidades definidas e, portanto não valida as hipóteses.

\subsection{Ciclo II}

\section{- Fase de conhecimento}

Partindo da premissa que essa fase já está compreendida por todos, foram apenas redefinidas algumas hipóteses e outras definidas, de acordo com a Tabela 3.

Tabela 3. Hipóteses de Valor definidas (Ciclo II).

\begin{tabular}{|l|l|}
\hline \multicolumn{2}{|c|}{ Hipóteses de Valor } \\
\hline $\mathbf{1}$ & O usuário tem interesse em acessar o Rota Urbana via versão móvel \\
\hline $\mathbf{2}$ & O usuário tem interesse em saber pontos de referência de uma parada. \\
\hline $\mathbf{3}$ & O usuário tem interesse em cadastrar as paradas que ele conhece. \\
\hline $\mathbf{4}$ & $\begin{array}{l}\text { O usuário tem interesse em saber quais linhas de ônibus que passam em } \\
\text { determinados pontos da cidade. }\end{array}$ \\
\hline $\mathbf{5}$ & $\begin{array}{l}\text { O usuário tem interesse em ter uma listagem de todas as linhas de ônibus da } \\
\text { cidade para selecionar cada uma delas para visualizar sua rota. }\end{array}$ \\
\hline
\end{tabular}

- Fase de Planejamento

Foi discutido que a complexidade das hipóteses a serem testadas, estaria de acordo com o tempo estipulado para o término do ciclo e, que esse tempo seria mais curto que o anterior. Foi acordado que se manteria maior engajamento para a preparação para tal experimento, bem como a divisão da equipe para realizá-los seria divida corretamente. Assim foram redefinidos os indicadores vinculados as hipóteses definidas.

\section{- Fase de Execução}

Assim como a fase de execução do ciclo anterior, esta foi feita de modo remoto e colaborativo com todos os integrantes. Esta fase foi satisfatória e as funcionalidades foram desenvolvidas de acordo com o planejado e no tempo estipulado para a validação de todas as hipóteses. A equipe já era mais conhecedora da metodologia e, portanto mais ágil na preparação do MVP.

\section{- Fase de Medição e Análise}

Os testes de hipóteses foram feitos em um período curto de dez dias, sendo que a duração total do ciclo durou vinte e sete dias, o que representa menos de $1 / 3$ da duração do ciclo I. No período de teste, houve um total de 613 visitas no site web do Rota 
Urbana, sendo que existe 109 instalações do aplicativo para dispositivos móveis nos celulares dos usuários. A taxa de aceitação e rejeição de visitas para o site web foi de $45,71 \%$ e $54,29 \%$, respectivamente.

Os números representativos do experimento de cada indicador se encontram na Tabela 4, considerando a taxa de aceitação.

Tabela 4. Resultado dos Experimentos (Ciclo II).

\begin{tabular}{|l|l|l|}
\hline \multicolumn{1}{|c|}{ Indicadores } & \multicolumn{1}{|c|}{ Resultados dos Experimentos } \\
\hline $\mathbf{1}$ & $\begin{array}{l}\text { Percentual de usuários que traça rotas entre dois pontos } \\
\text { e visualizam as rotas na versão móvel, maior que o } \\
\text { percentual total de usuários que acessaram nesse } \\
\text { período. }\end{array}$ & $\begin{array}{l}15 \text { (13,76\%) usuários traçaram } \\
\text { rotas entre dois pontos e 14 } \\
(12,84 \%) \text { usuários clicaram em } \\
\text { visualizar rotas. }\end{array}$ \\
\hline $\mathbf{2}$ & $\begin{array}{l}\text { Percentual de visitas que clica sobre as paradas para } \\
\text { abrir o texto de informações e pontos de referência da } \\
\text { mesma, maior que a metade do total de visitas que } \\
\text { acessaram nesse período. }\end{array}$ & $\begin{array}{l}23(8,22 \%) \text { visitas clicaram nas } \\
\text { paradas de ônibus 1. }\end{array}$ \\
\hline $\mathbf{3}$ & $\begin{array}{l}\text { Percentual de usuários que cadastra as paradas maiores } \\
\text { que a metade do total de usuários que acessaram nesse } \\
\text { período }\end{array}$ & $\begin{array}{l}(0,36 \%) \\
\text { paradas usuário cadastrou }\end{array}$ \\
\hline $\mathbf{4}$ & $\begin{array}{l}\text { Percentual de visitas que acessa a página inicial do } \\
\text { sistema e seleciona dois pontos para saber linhas que } \\
\text { passam perto desses dois pontos, maior que a metade do } \\
\text { total de visitas que acessaram nesse período. }\end{array}$ & $\begin{array}{l}205(73,21 \%) \text { visitas traçaram } \\
\text { rotas }\end{array}$ \\
\hline $\mathbf{5}$ & $\begin{array}{l}\text { Percentual de visitas que navega até a página „Todas as } \\
\text { Rotas }{ }^{\text {ce }} \text { para visualizar algum(as) rota(s) específica(s) }\end{array}$ & $\begin{array}{l}90(32,14 \%) \text { visitas clicaram em } \\
\text { visualizar rotas }\end{array}$ \\
\hline
\end{tabular}

\section{Conclusões e Trabalhos Futuros}

A metodologia Lean Startup proporcionou para a Startup Rota Urbana análises sobre as hipóteses que testaram o seu produto. Foi capaz de perceber como o negócio caminhava através de testes com usuários reais. $\mathrm{O}$ entendimento das métricas acionáveis e de vaidade ajudou a identificar as métricas corretas para os indicadores. Inicialmente todos estavam construindo as funcionalidades para colher dados do tipo quantidade de visualizações, sem considerar a quantidade de usuários, o que de fato revelou o pouco interesse em determinadas funcionalidades, caso contrário, estaríamos sendo enganados pelas altas taxas de visualizações.

Entretanto, algumas dificuldades foram observadas, tais como: o entendimento de algumas técnicas da metodologia Lean Startup; falha durante o planejamento e na execução por inexperiência da equipe com a metodologia; quebra de paradigma, pois iniciaram um processo de desenvolvimento, em detrimento do outro que estavam habituados e a perda de foco pra desenvolver funcionalidades não planejadas. Mediante isso, a Startup compreendeu que construir funcionalidades ótimas, em detrimento das necessidades dos usuários não é a melhor maneira de construir um negócio.

Quanto a condução de pesquisa, houve algumas dificuldades durante a sua realização. A inexperiência da utilização da Pesquisa-ação provocou muitas dúvidas e, em certas ocasiões se confundia com o processo do Lean Startup, pois ambas enfatizam ciclos de melhoria com fases similares. Esse foi um dos motivos que instigou a proposta 
de modelo de encaixe das metodologias. Outra dificuldade encontrada foi a dúvida de como aplicar o Lean Startup, pois é uma metodologia nova e na literatura não se tem muitos trabalhos correlatos no âmbito de aplicações em Startups de software.

Em síntese, a metodologia foi importante para as descobertas de pontos críticos durante o desenvolvimento de produto no Rota Urbana, além de nortear sua situação atual. De fato, o Lean Startup se mostrou uma metodologia capaz de guiar processos estruturados nesta Startup, entretanto não se pode caracterizar o sucesso ou insucesso proveniente do uso do Lean Startup, pois se precisa de mais estudos neste âmbito.

Para evolução deste trabalho, é sugerida a realização de mais ciclos do Lean Startup; aplicar o modelo de encaixe realizado neste trabalho em mais de uma Startup para identificar pontos comuns (dificuldades, facilidades e impactos) e a junção de outros modelos de negócio em consonância com o Lean Startup, para a aplicação destes em outras, onde se combinaria os aspectos mais promissores de todas as metodologias.

\section{Referências}

BLANK, S. (2013). Why the lean start-up changes everything. Havard Business Review.

BLANK, S., DORF, B. (2012). The startup owneres manual: the step-by-step guide for building a great company. Califórnia: K\&S Ranch Press.

BRAGA, V. L. P. (2012) Utilização de plano de negócios, laço de aprendizagem e modelo de negócios canvas para a criação de startups. Monografia, Universidade Federal do São Carlos, São Carlos, São Paulo, Brasil.

DYBA, T., DINGSOYR, T. (2008). Empirical studies of agile software development: a systematic review. Science Direct.

GARCIA, L. (2012). Como desenvolver novos produtos usando metodologias ágeis. Recuperado em 20 de Dezembro de 2013, de http://garciasbr.wordpress.com/2012/02/06/mvp/

GRIN, et al. (2012). Desenvolvimento de políticas públicas de fomento ao empreendedorismo em estados e municípios. Recuperado em 15 de Novembro de 2013,dehttp://ceapg.fgv.br/sites/ceapg.fgv.br/files/file/Pesquisas/POLITICAS_PUBL ICAS_site.pdf

GUSTAFSSON, A., QVILLBERG, J. (2012). Implementing lean startup methodology an evaluation. Dissertação, Chalmers University of Technology, Gotemburgo, Suécia.

KRAFTA, L., FREITAS, H., MARTENS, C. D. P., ANDRESs, R. (2007). O Método de pesquisa-ação: um estudo em uma empresa de coleta e análise de dados. Revista Quanti \&Quali.

LINDGREN, R., HENFRIDSSON, O., SCHULTZ, U. (2004). Design principles for competence managemente systems: a synthesis of an action research study.

MEIRA, S. (2013) Novos negócios inovadores de crescimento empreendedor no Brasil. Rio de Janeiro: Casa da Palavra.

OLIVEIRA, L. L. (2005). Pesquisa-ação: Uma Introdução Metodológica. (D. Tripp, Trad.). São Paulo: Educação e Pesquisa. (Obra original publicada em 2002).

PATZ M. (2013). Lean startup methodology - adding an experimental learning perspective to the enterpreneurial process. Dissertação, Universiteit Twente, Holanda. 